\title{
Cost and cost-effectiveness of tuberculosis treatment shortening: a model-based analysis
}

\author{
G. B. Gomez ${ }^{1,2^{*}}$, D. W. Dowdy ${ }^{3}$, M. L. Bastos ${ }^{4,5}$, A. Zwerling ${ }^{3}$, S. Sweeney ${ }^{2}$, N. Foster ${ }^{6}$, A. Trajman ${ }^{4,5,7}$, M. A. Islam ${ }^{8}$, \\ S. Kapiga ${ }^{9}$, E. Sinanovic ${ }^{6}$, G. M. Knight ${ }^{10}$, R. G. White ${ }^{10}$, W. A. Wells ${ }^{11,13}$, F. G. Cobelens ${ }^{1,12}$ and A. Vassall ${ }^{2}$
}

\begin{abstract}
Background: Despite improvements in treatment success rates for tuberculosis (TB), current six-month regimen duration remains a challenge for many National TB Programmes, health systems, and patients. There is increasing investment in the development of shortened regimens with a number of candidates in phase 3 trials.

Methods: We developed an individual-based decision analytic model to assess the cost-effectiveness of a hypothetical four-month regimen for first-line treatment of TB, assuming non-inferiority to current regimens of six-month duration. The model was populated using extensive, empirically-collected data to estimate the economic impact on both health systems and patients of regimen shortening for first-line TB treatment in South Africa, Brazil, Bangladesh, and Tanzania. We explicitly considered 'real world' constraints such as sub-optimal guideline adherence.

Results: From a societal perspective, a shortened regimen, priced at USD1 per day, could be a cost-saving option in South Africa, Brazil, and Tanzania, but would not be cost-effective in Bangladesh when compared to one gross domestic product (GDP) per capita. Incorporating 'real world' constraints reduces cost-effectiveness. Patient-incurred costs could be reduced in all settings. From a health service perspective, increased drug costs need to be balanced against decreased delivery costs. The new regimen would remain a cost-effective option, when compared to each countries' GDP per capita, even if new drugs cost up to USD7.5 and USD53.8 per day in South Africa and Brazil; this threshold was above USD1 in Tanzania and under USD1 in Bangladesh.
\end{abstract}

Conclusion: Reducing the duration of first-line TB treatment has the potential for substantial economic gains from a patient perspective. The potential economic gains for health services may also be important, but will be context-specific and dependent on the appropriate pricing of any new regimen.

Keywords: Tuberculosis, Cost-effectiveness, Economic evaluation, New technologies

\section{Background}

Globally, despite advances in diagnostic technologies and treatment success rates, tuberculosis (TB) remains a substantial health problem [1]. A major challenge faced by National TB Programs and patients is the length and complexity of existing regimens. New shortened regimens have potential advantages: improving outcomes

\footnotetext{
* Correspondence: g.gomez@aighd.org

${ }^{1}$ Amsterdam Institute for Global Health and Development and Department of Global Health, Academic Medical Center, University of Amsterdam, Trinity Building C, Pietersbergweg 17, Amsterdam 1105 BM, The Netherlands

${ }^{2}$ Department of Global Health and Development, London School of Hygiene and Tropical Medicine, London, UK

Full list of author information is available at the end of the article
}

through increasing adherence; decreasing time to cure; reducing costs incurred by patients; and reducing treatment delivery costs incurred by health systems [2, 3]. These potential health and economic gains have motivated increasing investments in new regimens in recent years [4-6]. Although recent trials of new TB regimens, such as four-month moxifloxacin-based regimens, have so far proved unsuccessful [4], larger-scale trials including new drugs are ongoing [7]. Understanding the potential benefits and costs of introducing new $\mathrm{TB}$ regimens in different epidemiological and health system contexts is therefore critical in the context of the post-2015 global TB Targets. 
Previous efforts to quantify the economic and health impact of shortened regimens have been limited; and these efforts have focused on general analyses that are not specific to any particular setting. While such studies can identify key drivers of cost-effectiveness at a general level, further work is required to characterize the costeffectiveness of new TB regimens at country level [8-11]. Importantly, none of the previous studies were parameterized with locally-collected data; or reflect the influence of health system constraints. Incorporating sound empirical data on health service costs is critical, given that one of the central aims of introducing new shortened first-line regimens is to achieve a reduction in health system burden from TB treatment. Moreover, while previous studies have included estimates of provider costs, none of these studies have considered the potential cost savings to patients. The potential benefits in terms of patient costs are important in the light of the post-2015 global TB target of ensuring that no-one suffers catastrophic expenditures from $\mathrm{TB}$, in the context of Universal Health Coverage.

We explore the cost and cost-effectiveness of introducing a new shortened TB regimen in four countries. We use primary data on both patient and provider incurred costs; and incorporate data on local patterns of TB treatment delivery in our estimates. The aim is to guide further development and in-country adoption of shortened first-line TB regimens.

\section{Methods \\ Model}

We used a decision analytic model to compare the costeffectiveness of a hypothetical four-month regimen to the existing standard of care, a six-month regimen for first-line treatment of TB. Our primary outcomes were the incremental cost per disability-adjusted life-year (DALY) averted, and incremental average total, health service and patient incurred costs. Our population was a cohort 10,000 individuals with newly diagnosed pulmonary TB and no previous treatment history, characterised for four settings, South Africa, Bangladesh, Brazil and Tanzania (Additional file 1: Table S1). The model defined each individual patient in the cohort by smear status (positive or negative), HIV (positive or negative), antiretroviral treatment (ART) (treated or not treated), and resistance profile (pan-sensitive or resistant to at least rifampicin) to reflect the multi-drug resistant TB (MDR-TB) burden in each country.

The treatment approach was informed by national guidelines, which are laid out in table S2 (Additional file 1). At the end of each month, patients could either continue on or complete treatment, be lost to follow-up (default), die, or (in the final month of treatment) fail. Loss to follow-up is defined as a patient whose treatment is interrupted for two consecutive months [12]. After loss to follow-up, we assumed patients may re-enter care, thereafter classified as previously treated. The duration of treatment before default determined the treatment algorithm to be followed once the patient returned to care. The probability of cure after default also depended on the duration of treatment completed before defaulting as per the literature of shorter-course regimens [13]. Patients stopping treatment in the first two months were assumed to receive no benefit from the treatment and have a probability of cure equivalent to the probability of spontaneous recovery. Thereafter, patients stopping treatment received partial benefit from the treatment and have a probability of cure proportional to the length of treatment completed [13].

Treatment failure was defined as a smear positive result at five months or later during treatment [12]. After treatment failure, we assumed that patients complete either a second round of treatment (standard first line in South Africa and Brazil or one course of retreatment in Bangladesh and Tanzania, where retreatment regimens are available) or, where they have been diagnosed as rifampicin-resistant after drug susceptibility testing (DST), one course of MDR-TB treatment. If they failed the second round of treatment, they were considered not to receive additional treatment, and become chronic TB cases until death. Cases of relapse (a new episode of TB after a period of no TB) were excluded [12].

The model was built using TreeAge software. Several schematics of the model are presented in the Additional file 1: Figure S1 to Figure S3, while the main parameter values used are presented in Table 1.

\section{Intervention}

We modelled a non-inferior four-month new regimen compared to the current six-month regimen, on the assumption that non-inferiority would be the minimal aim of new trials. Non-inferiority refers to the efficacy of the regimen. Given this conservative assumption, the potential impact of the new shortened regimen on health outcomes results from an increase in effectiveness due to a higher probability of patients completing a shortened treatment regimen and a higher probability of cure if patients stop treatment early after taking at least two months of the shortened regimen. Introduction of the new regimen into practice was set to follow national TB treatment guidelines with regards to DST algorithms, eligibility for first-line therapy, monitoring, standardised MDR treatment, directly observed therapy (DOT), and ART eligibility for HIV/TB patients (Additional file 1: Table S3). Where DST was available, we assumed that a case resistant to rifampicin will not be eligible for either the new or current firstline treatment regimen. 
Table 1 Parameters

\begin{tabular}{|c|c|c|c|c|c|}
\hline Parameter, value [range] & South Africa & Brazil & Bangladesh & Tanzania & Reference \\
\hline \multicolumn{6}{|l|}{ Population distribution } \\
\hline Smear-positivity: HIV-negative, HIV-positive no ART, HIV-positive ART & $0.69,0.35,0.45$ & & & & [29] [30] \\
\hline MDR prevalence, among new patients & $1.8 \%$ & $1.4 \%$ & $1.4 \%$ & $1.1 \%$ & {$[1,31,32]$} \\
\hline Prevalence of HIV in TB patients & $62 \%$ & $17 \%$ & $3 \%$ & $37 \%$ & {$[1,33,34]$} \\
\hline \multicolumn{6}{|l|}{ Diagnosis of TB } \\
\hline TB diagnosis, sensitivity, smear, HIV negative & $0.72[0.62-0.82]$ & & & & {$[29,35]$} \\
\hline TB diagnosis, sensitivity, smear, HIV positive & $0.47[0.51-0.43]$ & & & & {$[29,35]$} \\
\hline TB diagnosis, sensitivity, GeneXpert, smear positive & $0.98[0.97-0.99]$ & & & & {$[36]$} \\
\hline TB diagnosis, sensitivity, GeneXpert, smear negative & $0.68[0.59-0.75]$ & & & & {$[36]$} \\
\hline TB diagnosis, specificity, GeneXpert, all & $0.98[0.97-0.99]$ & & & & {$[36]$} \\
\hline TB diagnosis, specificity, smear, all & 1 & & & & assumption \\
\hline RIF-resistance diagnosis, sensitivity, GeneXpert, all & $0.94[0.87-0.97]$ & & & & {$[36]$} \\
\hline RIF-resistance diagnosis, specificity, GeneXpert, all & 0.98 [0.97-0.99] & & & & {$[36]$} \\
\hline \multicolumn{6}{|l|}{ Outcomes (first line treatment) } \\
\hline \multicolumn{6}{|l|}{ Pr mortality: } \\
\hline Pan-sensitive, HIV negative & $0.03[0.02-0.03]$ & & & & {$[37]$} \\
\hline MDR, HIV negative & $0.11[0.08-0.13]$ & & & & {$[37]$} \\
\hline Pan-sensitive, HIV positive, ART & $0.07[0.05-0.09]$ & & & & {$[38]$} \\
\hline Pan-sensitive, HIV positive, no ART & $0.33[0.30-0.43]$ & & & & {$[38]$} \\
\hline MDR, HIV positive, ART & $0.11[0.10-0.21]$ & & & & {$[38,39]$} \\
\hline MDR, HIV positive, no ART & $0.85[0.72-0.98]$ & & & & {$[39]$} \\
\hline \multicolumn{6}{|l|}{ Pr cure, if treatment completed: } \\
\hline Pan-sensitive & $0.97[0.95-0.98]$ & & & & {$[13]$} \\
\hline MDR & $0.50[0.40-0.55]$ & & & & {$[37]$} \\
\hline \multicolumn{6}{|l|}{ Pr cure, if less than 2 months treatment completed } \\
\hline HIV negative, smear negative & $0.20[0.15-0.25]$ & & & & {$[40-42]$} \\
\hline HIV negative, smear positive & $0.30[0.20-0.40]$ & & & & {$[40-42]$} \\
\hline HIV positive, smear neg/pos, no ART & $0[0-0.05]$ & & & & {$[40-42]$} \\
\hline HIV positive, smear negative, ART & $0.10[0.05-0.15]$ & & & & {$[40-42]$} \\
\hline HIV positive, smear positive, ART & $0.05[0-0.10]$ & & & & {$[40-42]$} \\
\hline \multicolumn{6}{|l|}{ Pr cure, if default at (standard 6 mo regimen): } \\
\hline 2-3 months, pan-sensitive & $0.68[0.50-0.80]$ & & & & {$[43]$} \\
\hline 2-3 months, MDR & $0.35[0.21-0.45]$ & & & & {$[43]$} \\
\hline 4-5 months, pan-sensitive & $0.86[0.70-0.89]$ & & & & {$[44,45]$} \\
\hline 4-5 months, MDR & $0.48[0.29-0.51]$ & & & & {$[44,45]$} \\
\hline \multicolumn{6}{|l|}{ Pr cure, if default at (new 4 mo regimen): } \\
\hline 2-3 months, pan-sensitive & $0.74[0.57-0.83]$ & & & & Assumption \\
\hline 2-3 months, MDR & $0.38[0.23-0.47]$ & & & & Assumption \\
\hline \multicolumn{6}{|l|}{ Outcomes (second round of treatment) } \\
\hline Pr patients returning to care after default & $0.21[0.10-0.70]$ & & & & {$[46]$} \\
\hline Pr patients staying in care after failure & $0.60[0.40-0.80]$ & & & & Assumption \\
\hline \multicolumn{6}{|l|}{ Pr mortality } \\
\hline HIV negative/positive ART, pan-sensitive & $0.06[0.04-0.07]$ & & & & {$[37]$} \\
\hline HIV negative/positive ART, MDR & $0.15[0.10-0.20]$ & & & & [37] \\
\hline
\end{tabular}


Table 1 Parameters (Continued)

\begin{tabular}{|c|c|c|c|c|c|}
\hline HIV positive no ART, pan-sensitive & \multicolumn{4}{|l|}{$0.33[0.30-0.43]$} & [38] \\
\hline HIV positive no ART, MDR & \multicolumn{4}{|l|}{$0.85[0.72-0.98]$} & [39] \\
\hline \multicolumn{6}{|l|}{ MDR treatment and long term outcomes } \\
\hline Pr cure, MDR treatment (including default) & \multicolumn{4}{|l|}{$0.65-0.80$} & [47] \\
\hline Mortality during MDR treatment & \multicolumn{4}{|l|}{0.10} & [48] \\
\hline $\begin{array}{l}\text { Pr long term mortality (chronic TB patient or } \\
\text { default patient if no return to care) }\end{array}$ & \multicolumn{4}{|l|}{$0.75[0.50-0.99]$} & [48] \\
\hline Self-cure among chronic TB patients & \multicolumn{4}{|l|}{0.01} & [48] \\
\hline \multicolumn{6}{|l|}{ DALYs averted (discounted at 0.03/year) } \\
\hline HIV negative, smear negative & $12.5[11.3-13.8]$ & $19.3[17.4-21.3]$ & $15.3[13.7-16.8]$ & $14.2[12.8-15.7]$ & Additional file 1 \\
\hline HIV negative, smear positive & $15.2[13.7-16.7]$ & 22.0 [19.8-24.2] & 179 [16.1-19.7] & 16.9 [15.2-18.6] & Additional file 1 \\
\hline HIV positive, smear negative, no ART & $1.8[1.6-2.0]$ & $1.8[1.6-2.0]$ & $1.8[1.6-2.0]$ & $1.8[1.6-2.0]$ & Additional file 1 \\
\hline HIV positive, smear positive, no ART & $2.0[1.8-2.2]$ & $2.0[1.8-2.2]$ & $2.0[1.8-2.2]$ & $2.0[1.8-2.2]$ & Additional file 1 \\
\hline HIV positive, smear negative, ART & $9.9[8.9-10.9]$ & $9.9[8.9-10.9]$ & $9.9[8.9-10.9]$ & $9.9[8.9-10.9]$ & Additional file 1 \\
\hline HIV positive, smear positive, ART & $10.1[9.1-11.1]$ & $10.1[9.1-11.1]$ & $10.1[9.1-11.1]$ & $10.1[9.1-11.1]$ & Additional file 1 \\
\hline
\end{tabular}

HIV human immunodeficiency virus, TB tuberculosis, ART antiretroviral treatment, MDR multidrug resistant, $\operatorname{Pr}$ probability

Parameters with one value are included in the model as point estimates; parameters with a value and a range were included in the model as triangular distributions; parameters with only a range of two values were included in the model as a uniform distribution

\section{Costs}

Costs related to TB treatment were estimated from a societal perspective in South Africa, Bangladesh, Brazil, and Tanzania, using extensive primary costing surveys. All cost estimates are presented in 2013 USD [14, 15]. Summary costs are presented in Table 2; full details on the costing methodology can be found in publications elsewhere $[3,16-19]$ and summarized in table S4, while detailed unit costs are presented in Additional file 1: Table S5.

\section{Health service-related costs}

We included service provider costs for all countries and, where feasible, we also included costs incurred above site level, such as monitoring and evaluation and coordination costs. In South Africa, we sourced unit cost data from the "Xpert for TB: Evaluating a New Diagnostic" (XTEND) trial. Data from this trial were collected from eight clinics, 20 laboratories and three MDR treatment sites [18]. In Bangladesh, Tanzania, and Brazil, we conducted health facility costing studies in nine, six, and ten sites respectively. We used a systematic review of previous costing studies to support our estimates, describe parameter bounds and assess representativeness, and, in the case of Tanzania (as we were not able to cost from any community-based DOT activities for feasibility reasons), community-based TB-specific costs were also sourced from the literature [20]. Other costs, such as MDR-TB and ART treatment costs, were sourced from the literature [21-24]. We conducted our primary analysis using a new regimen cost of USD1 per day, in line with previous studies [8].

\section{Patient-related costs}

Patient data from Bangladesh and Tanzania on direct and indirect costs were sourced from a recent study [3]. In South Africa, XTEND study's patient cost data were used [17]. In Brazil, we interviewed 126 patients from ten facilities located between the municipality of Rio and peri-urban areas ensuring a mix of wealthier and poorer areas [16]. A review of previous costing studies was used to assess the representativeness and explore uncertainty; and to source information on patient costs for ART in HIV co-infected patients and MDR-TB patients in all countries, except South Africa.

\section{Analysis}

We calculated DALYs averted from patients being cured using the standard formula [25]. Further details on DALY assumptions can be found in Additional file 1: Table S6. We then modelled the intervention using a two-stage approach. Firstly, we modelled the full implementation of the TB treatment guidelines (including full adherence to ART treatment guidelines and MDR treatment coverage) against a locally-parameterised context (epidemiological and study population characteristics). Default rate in this scenario has been set to be at a programmatic minimum of $1-2 \%$, as observed in the recent trial for shortened first-line regimens [4].

In a second stage, we explored the sensitivity of our results to a scenario reflecting current practice, where providers did not adhere to the guidelines and patients have a higher rate of default, reflecting 'real world' conditions. Default in this scenario is equal to the one reported by countries in the 2014 Global TB report [1]. 
Table 2 Costs

\begin{tabular}{|c|c|c|c|c|c|}
\hline & South Africa & Brazil & Bangladesh & Tanzania & Reference \\
\hline \multicolumn{6}{|l|}{ a. Guidelines } \\
\hline \multicolumn{6}{|l|}{ Healthcare provider costs } \\
\hline First-line treatment, IP, $1 \mathrm{mo}$ (excl drugs) & $200(152-230)$ & $333(117-479)$ & $17(12-21)$ & $65(24-106)$ & {$[16,18,19]$} \\
\hline First-line treatment, CP, $1 \mathrm{mo}$ (excl drugs) & $54(41-62)$ & $333(117-479)$ & $11(7-15)$ & $16(7-24)$ & {$[16,18,19]$} \\
\hline Drugs, first-line, IP, $1 \mathrm{mo}$ & 16 & $7(6-9)$ & $7(6-8)$ & 6 & {$[16,18-20]$} \\
\hline Drugs, first-line, CP, $1 \mathrm{mo}$ & 19 & $4(3-6)$ & $3(3-3)$ & 2 & {$[16,18-20]$} \\
\hline Retreatment: all & $\mathrm{n} / \mathrm{a}$ & $n / a$ & $213(160-266)$ & $430(310-549)$ & {$[16,18,19]$} \\
\hline MDR treatment: all & $10,215(8,619-24,580)$ & $5,223(4,800-5,348)$ & $4,262(3,836-4,688)$ & $2,507(2,454-2,561)$ & {$[16,18,19]$} \\
\hline ART cost in year 1 & $1,128(1,117-1,139)$ & $5,875(5,288-6,463)^{a}$ & $800(720-880)$ & $315(283-346)$ & {$[21,22,49-52]$} \\
\hline ART cost per year (after year 1) & $639(575-703)$ & & $600(540-660)$ & $277(249-304)$ & {$[21,22,49-52]$} \\
\hline \multicolumn{6}{|l|}{ Patient costs } \\
\hline First-line treatment, IP, $1 \mathrm{mo}$ & $149(87-164)$ & $40(8-131)$ & $314(283-346)$ & $186(167-204)$ & {$[3,16,17]$} \\
\hline First-line treatment, $C P, 1 \mathrm{mo}$ & $117(34-129)$ & $40(8-131)$ & $31(28-34)$ & $44(40-48)$ & {$[3,16,17]$} \\
\hline Retreatment: all & $\mathrm{n} / \mathrm{a}$ & $\mathrm{n} / \mathrm{a}$ & $135(121-148)$ & $354(319-390)$ & {$[3,16,17]$} \\
\hline MDR treatment: all & $3,319(2,987-3,650)$ & $280(102-1142)$ & $213(192-234)$ & $454(409-499)$ & {$[3,16,17]$} \\
\hline ART cost in year 1 & $106(96-117)$ & $23(4-43)$ & $8(7-8)$ & $24(22-26)$ & [53] \\
\hline ART cost per year (after year 1) & $85(77-93)$ & $9(2-17)$ & $3(3-3)$ & $10(9-11)$ & [53] \\
\hline Cost per visit to healthcare facility & $8(7-9)$ & $5(1-9)$ & $2(1-2)$ & $5(4-5)$ & {$[3,16,17]$} \\
\hline \multicolumn{6}{|l|}{ b. Current } \\
\hline \multicolumn{6}{|l|}{ Healthcare provider costs } \\
\hline First-line treatment, IP, $1 \mathrm{mo}$ (excl drugs) & $61(40-96)$ & $133(59-285)$ & $17(12-21)$ & $35(24-45)$ & {$[16,18,19]$} \\
\hline First-line treatment, $C P, 1 \mathrm{mo}$ (excl drugs) & $16(11-26)$ & $133(59-285)$ & $11(8-15)$ & $16(7-24)$ & {$[16,18,19]$} \\
\hline Drugs, first-line, IP, $1 \mathrm{mo}$ & 16 & $7(6-9)$ & $7(6-8)$ & 6 & {$[16,18-20]$} \\
\hline Drugs, first-line, IP, $1 \mathrm{mo}$ & 19 & $4(3-6)$ & $3(3-3)$ & 2 & {$[16,18-20]$} \\
\hline Retreatment: all & $\mathrm{n} / \mathrm{a}$ & n/a & $213(160-266)$ & $429(310-549)$ & {$[16,18,19]$} \\
\hline MDR treatment: all & $10,215(8,619-24,580)$ & $5,223(4,800-5,348)$ & $4,262(3,836-4,688)$ & $2,507(2,454-2,561)$ & {$[16,18,19]$} \\
\hline ART cost in year 1 & $1,128(1,117-1,139)$ & $5,875(5,288-6,463)^{a}$ & $800(720-880)$ & $315(283-346)$ & {$[21,22,49-52]$} \\
\hline ART cost per year (after year 1) & $639(575-703)$ & & $600(540-660)$ & $277(249-304)$ & {$[21,22,49-52]$} \\
\hline \multicolumn{6}{|l|}{ Patient costs } \\
\hline First-line treatment, IP, $1 \mathrm{mo}$ & $60(35-66)$ & $40(8-131)$ & $314(283-346)$ & $144(139-149)$ & {$[3,16,17]$} \\
\hline First-line treatment, $\mathrm{CP}, 1 \mathrm{mo}$ & $27(8-30)$ & $40(8-131)$ & $31(28-34)$ & $41(37-44)$ & {$[3,16,17]$} \\
\hline Retreatment: all & $\mathrm{n} / \mathrm{a}$ & n/a & $135(121-148)$ & $354(319-390)$ & {$[3,16,17]$} \\
\hline MDR treatment: all & $3,319(2,987-3,650)$ & $280(102-1,142)$ & $213(192-234)$ & $454(409-499)$ & {$[3,16,17]$} \\
\hline ART cost in year 1 & $106(96-117)$ & $23(4-43)$ & $8(7-8)$ & $24(22-26)$ & [53] \\
\hline ART cost per year (after year 1) & $85(77-94)$ & $9(2-17)$ & $3(3-3)$ & $10(9-11)$ & [53] \\
\hline Cost per visit to healthcare facility & $8(7-9)$ & $5(1-9)$ & $2(1-2)$ & $5(4-5)$ & {$[3,16,17]$} \\
\hline
\end{tabular}

$I P$ intensive phase, $C P$ continuation phase, mo month, excl excluding, $A R T$ antiretroviral treatment, $M D R$ multidrug resistant, $D S T$ drug resistance testing ${ }^{a}$ Average cost per year

We considered non-adherence of two types: nonadherence to the coverage of complementary services (ART and MDR-TB treatment), which affects survival once treatment is completed, and non-adherence to first-line treatment monitoring (directly observed therapy, DOT) by providers. With respect to the former we applied the current coverage levels for ART and MDR-
TB treatment; with respect to the latter we allowed the unit costs (and patient costs) of both the standard of care and the new regimen to reflect current levels of DOT. Table 3 shows the coverage levels by scenario.

We used a probabilistic sensitivity analysis (Monte Carlo simulation) to randomly sample parameters from distributions (defined in Table 1), conducting 1,000 
Table 3 Scenario parameters: coverage levels for GeneXpert, MDR treatment and ART in HIV co-infected individuals

\begin{tabular}{|c|c|c|c|c|c|}
\hline & South Africa & Brazil & Bangladesh & Tanzania & reference \\
\hline \multicolumn{6}{|l|}{ All scenarios } \\
\hline GeneXpert coverage in new patients & $100 \%$ & $100 \%$ & $0 \%$ & $0 \%$ & assumption \\
\hline GeneXpert coverage in previously treated & $100 \%$ & $100 \%$ & $100 \%$ & $100 \%$ & assumption \\
\hline \multicolumn{6}{|l|}{ Guidelines } \\
\hline ART if $H I V / T B$ & $100 \%$ & $100 \%$ & $100 \%$ & $100 \%$ & {$[54-61]$} \\
\hline MDR treatment & $100 \%$ & $100 \%$ & $100 \%$ & $100 \%$ & {$[56,59,60,62]$} \\
\hline Default rate & $1-2 \%$ & $1-2 \%$ & $1-2 \%$ & $1-2 \%$ & [4] \\
\hline \multicolumn{6}{|l|}{ Current } \\
\hline ART if $\mathrm{HIV} / \mathrm{TB}$ & $66 \%$ & $54.7 \%$ & $100 \%$ & $73 \%$ & {$[1,63]$} \\
\hline MDR treatment & $60 \%$ & $44.5 \%$ & $15.4 \%$ & $12.3 \%$ & {$[1,64]$} \\
\hline Default rate & $8 \%[6-10]$ & $21 \%$ [19-23] & $2 \%[1.8-2.2]$ & $3 \%[2-4]$ & [1] \\
\hline
\end{tabular}

ART antiretroviral treatment, HIV human immunodeficiency virus, TB tuberculosis, MDR multidrug resistant. Current coverage of ART in HIV/TB co-infection as reported in Global TB report 2014 [1], except for Brazil where this is not reported. For Brazil, we calculated the coverage of ART in HIV/TB co-infection as 84\% ART coverage in general HIV patients [63] of 65\% TB patients knowing their HIV status. Current coverage of MDR TB treatment was calculated from the Global TB report 2014 [1] from the prevalence of MDR among new and retreatment patients times the number of notifications for new and retreatment patients respectively. This was considered the denominator (total number of MDR patients). The numerator (patients on MDR treatment) was sourced from the Global TB report 2014. For South Africa, we added the estimated current MDR coverage levels as per the National Department of Health [64]. Note: parameters with one value are included in the model as point estimates; parameters with a value and a range were included in the model as triangular distributions; parameters with only a range of two values were included in the model as a uniform distribution

simulations each of random populations of 10,000 individuals. We report the standard deviations and 95\% uncertainty ranges $\left(2.5^{\text {th }}\right.$ and $97.5^{\text {th }}$ percentiles). We explored the main drivers of uncertainty in our estimates in a series of one-way sensitivity analyses by varying each of the following variables over widest plausible ranges sourced from the literature: default rate during treatment, mortality during first-line treatment and after default, prevalence of MDR, no cure if treatment was partially completed, probability of returning to care after default, length of survival if on ART, and discount rate.

Finally, given the uncertainty around drug prices, we conducted a threshold analysis to examine the price for which the incremental cost-effectiveness ratio (ICER) of new TB treatment regimens crosses selected willingness-topay (WTP) thresholds. WTP was defined as a quarter, half, or one times the country-specific gross domestic product per capita for the year 2013, to acknowledge possible limited discretionary resources available, and thus effective opportunity costs, within health services in low and middle income countries. Future costs and health gains during the patient's lifetime were discounted at a rate of $3 \%$ per year.

We conducted and present this study following good reporting practices from published standards: the CHEERS statement (Additional file 2: Checklist), and the Bill and Melinda Gates Foundation's Methods for Economic Evaluation consensus [26, 27].

\section{Results}

Figure 1 shows the cost savings in TB-related costs per new TB patient by country, scenario, and payer. Shortening the treatment regimen from six to four months was projected to reduce patient costs in all settings. These savings are estimated to be highest in Brazil $(-30 \%)$, then South Africa (-25\%) and lowest in Bangladesh (-5\%), where the delivery of TB services at the community level minimizes patient costs [3]. From a health service perspective, there is a trade-off between increased drug costs and decreased delivery costs. In settings where existing drug and delivery costs were low, the new regimen (assumed drug price of USD1 per day) increased overall health service costs (USD75 in Bangladesh (60\% increase), USD72 in Tanzania, (32\% increase)). In contrast, where existing drug and delivery costs are higher, a shorter-course regimen was cost saving (-USD20 in South Africa, 1.7\% reduction; and -USD463 in Brazil, 24\% reduction) (Fig. 1).

When taking into account 'real world' provision of TB treatment, these cost savings were substantially lower in South Africa and Brazil. In this case the shortened regimen is no longer cost saving, but results in an $8.4 \%$ increase in cost of first-line TB treatment in South Africa, while cost savings are reduced to USD160 in Brazil. Examining the costs related to HIV, we found that the introduction of a new shortened first-line regimen for TB does not substantially affect the incremental costs related to ART (Additional file 1: Table S7).

Although modelling non-inferiority, we observe some benefit for the patient cohort, in terms of mortality reduction and treatment completion (see Additional file 1: Table S8) from a reduction in default. These benefits are larger in high default settings; and in our 'real world' analysis. However, this positive effect on mortality and DALYs averted is modest, across all scenarios and countries (Table 4). 


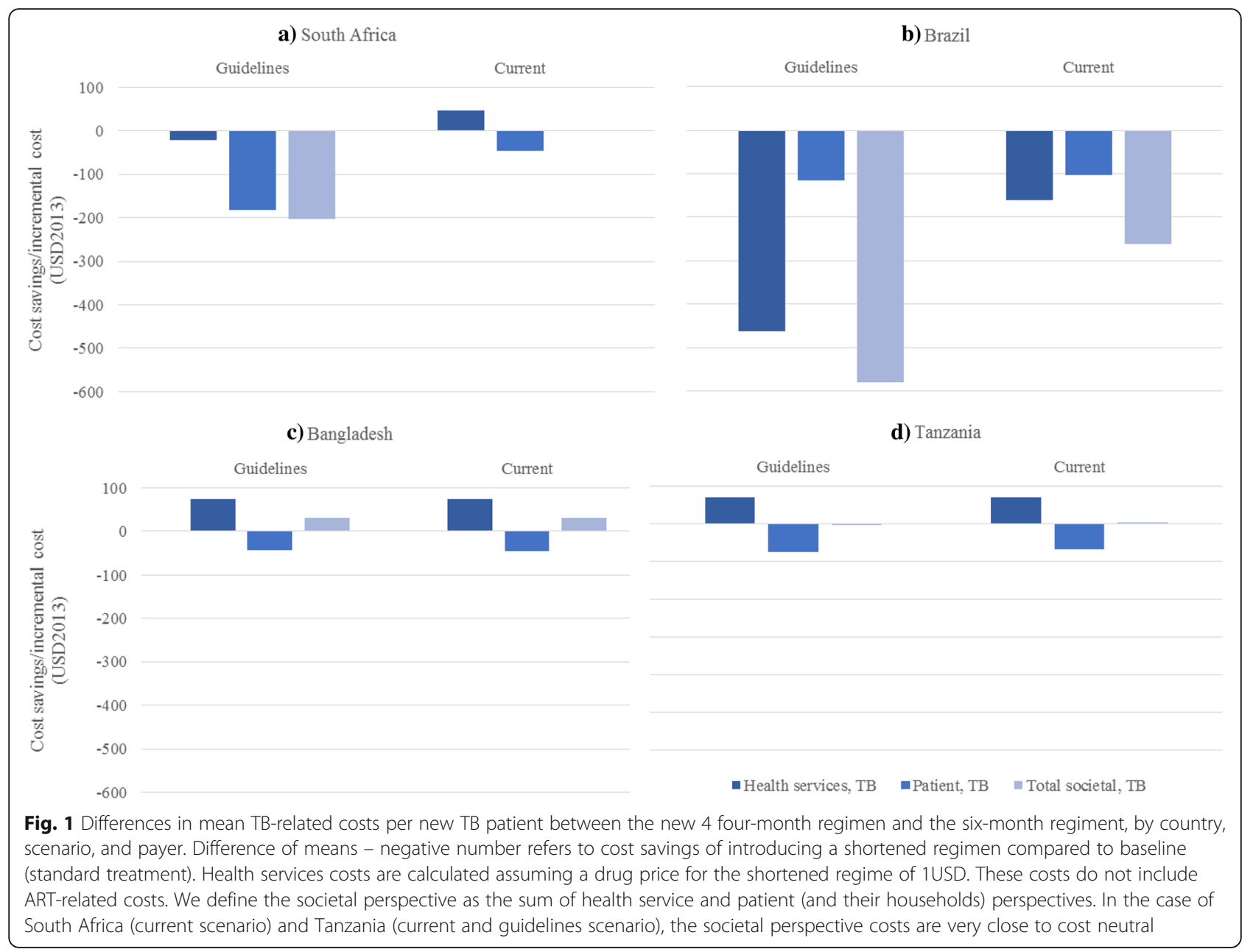

Cost-effectiveness varies by setting when we assume the drugs for the shorter regimen to be priced at USD1 per day (Table 4). In South Africa, only the current scenario was not estimated to be cost saving but remained a costeffective choice (mean USD13.6 per DALY averted). In Tanzania, new shortened regimens in the guideline scenario might be cost saving, but when 'real world' considerations are taken into account, extra investment is needed. However, this extra investment was cost-effective (mean USD161 per DALY averted). In contrast, in Bangladesh, across both scenarios, this investment was not costeffective when compared to one GDP per capita as a WTP threshold (mean USD1,472 and 1,220 per DALY averted in guidelines and current scenarios, respectively), reflecting the trade-off between the higher drug prices assumed for the new regimen and low service delivery costs. In one-way sensitivity analyses, our conclusions were stable to most of the assumptions made (Fig. 2). Cost-effectiveness was most sensitive to existing health service costs for treatment delivery and default rates. In addition to these, in Brazil and South Africa (Fig. 2a and b), a higher prevalence of MDR resulted in an increase in cost savings, while a high probability of returning to care after default reduced the incremental benefits observed. In Bangladesh (Fig. 2c), a higher prevalence in MDR changed from an assessment of the new regimen not being costeffective to being cost-saving. The new shortened regimen remained cost-effective in Tanzania under all analyses.

Using a threshold analysis (Fig. 3), we estimated that in settings with low treatment delivery costs (Bangladesh and Tanzania) the threshold price for achieving costeffectiveness is approximately USD1 per day and it remains at this level if different assumptions of adherence to guidelines are made. In settings with higher treatment delivery costs (Brazil and South Africa), the threshold price varies substantially depending on how closely current practice adheres to guidelines. In general, the threshold drug price are reduced if treatment guidelines are totally adhered to (mainly due to a higher cost in health service delivery and better effect).

\section{Discussion}

We present a four-country economic evaluation of the introduction of a new hypothetical four-month $\mathrm{TB}$ 
Table 4 DALYs averted per country and scenario and incremental cost-effectiveness ratios (societal perspective), if drug price is 1 USD per day

\begin{tabular}{|c|c|c|c|}
\hline & & Guidelines & Current \\
\hline \multicolumn{4}{|l|}{ South Africa } \\
\hline \multirow[t]{2}{*}{ Current $6 \mathrm{mo} R \mathrm{x}$} & DALY averted, mean (SD) & $9.97(0.23)$ & $8.26(0.18)$ \\
\hline & DALY averted, median (2.5-97.5) & $9.97(9.52-10.42)$ & $8.26(7.92-8.61)$ \\
\hline \multirow[t]{5}{*}{ New 4mo Rx } & DALY averted, mean (SD) & $10.0(0.23)$ & $8.37(0.18)$ \\
\hline & DALY averted, median (2.5-97.5) & $9.99(9.55-10.43)$ & $8.37(8.04-8.72)$ \\
\hline & mean difference (\%) & $0.02(0.07)$ & $0.11(0.03)$ \\
\hline & ICER, median (2.5-97.5) & CS $(C S-26,065)$ & 16.9 (CS-897) \\
\hline & ICER, calculated mean & CS & 13.6 \\
\hline GDP per capita & & 6,618 & \\
\hline \multicolumn{4}{|l|}{ Brazil } \\
\hline \multirow[t]{2}{*}{ Current $6 \mathrm{mo}$ Rx } & DALY averted, mean (SD) & $16.50(0.51)$ & $14.68(0.51)$ \\
\hline & DALY averted, median (2.5-97.5) & $16.52(15.54-17.48)$ & $14.67(13.74-15.65)$ \\
\hline \multirow[t]{5}{*}{ New 4 mo Rx } & DALY averted, mean (SD) & $16.54(0.51)$ & $15.18(0.51)$ \\
\hline & DALY averted, median (2.5-97.5) & $16.56(15.55-17.54)$ & $15.16(14.25-16.16)$ \\
\hline & mean difference (\%) & $0.04(0.06)$ & $0.50(0.08)$ \\
\hline & ICER, median (2.5-97.5) & CS (CS-116,251) & CS (CS-362) \\
\hline & ICER, calculated mean & CS & CS \\
\hline GDP per capita & & 11,208 & \\
\hline \multicolumn{4}{|l|}{ Bangladesh } \\
\hline \multirow[t]{2}{*}{ Current 6 mo Rx } & DALY averted, mean (SD) & $16.19(0.53)$ & $16.17(0.51)$ \\
\hline & DALY averted, median (2.5-97.5) & $16.20(15.20-17.21)$ & $16.16(15.17-17.15)$ \\
\hline \multirow[t]{5}{*}{ New $4 \mathrm{mo} R x$} & DALY averted, mean (SD) & $16.21(0.53)$ & $16.20(0.51)$ \\
\hline & DALY averted, median (2.5-97.5) & $16.22(15.19-17.24)$ & $16.18(15.19-17.15)$ \\
\hline & mean difference (\%) & $0.02(0.06)$ & $0.02(0.06)$ \\
\hline & ICER, median (2.5-97.5) & 164 (CS-9,075) & 129 (CS-8,824) \\
\hline & ICER, calculated mean & 1,472 & 1,220 \\
\hline GDP per capita & & 829 & \\
\hline \multicolumn{4}{|l|}{ Tanzania } \\
\hline \multirow[t]{2}{*}{ Current 6 mo Rx } & DALY averted, mean (SD) & $13.66(0.36)$ & $12.97(0.36)$ \\
\hline & DALY averted, median (2.5-97.5) & $13.66(12.98-14.35)$ & $12.96(12.31-13.65)$ \\
\hline \multirow[t]{5}{*}{ New $4 \mathrm{mo} R x$} & DALY averted, mean (SD) & $13.68(0.36)$ & $13.00(0.36)$ \\
\hline & DALY averted, median (2.5-97.5) & $13.67(12.99-14.36)$ & $12.99(12.32-13.70)$ \\
\hline & mean difference (\%) & $0.02(0.04)$ & $0.03(0.05)$ \\
\hline & ICER, median (2.5-97.5) & CS (CS-12,252) & 39 (CS-3,937) \\
\hline & ICER, calculated mean & CS & 161 \\
\hline GDP per capita & & 695 & \\
\hline
\end{tabular}

Mo months, Rx treatment, DALY disability-adjusted life years, SD standard deviation, ICER incremental cost effectiveness ration, CS cost saving, GDP per capita gross domestic product per capita

regimen compared to the current six-month regimen. The cost-effectiveness of the new shortened regimen for first-line TB treatment varies substantially by setting and current treatment practice. We find that a new noninferior shortened regimen costing USD1 a day would likely be cost-saving in Brazil, South Africa, and
Tanzania, but not in Bangladesh, assuming full adherence to treatment guidelines. Potential health servicerelated cost savings are modest and are lower when 'real world' treatment practice is taken into account. Patient incurred cost savings are substantial in all settings, especially when services are facility-based rather than 


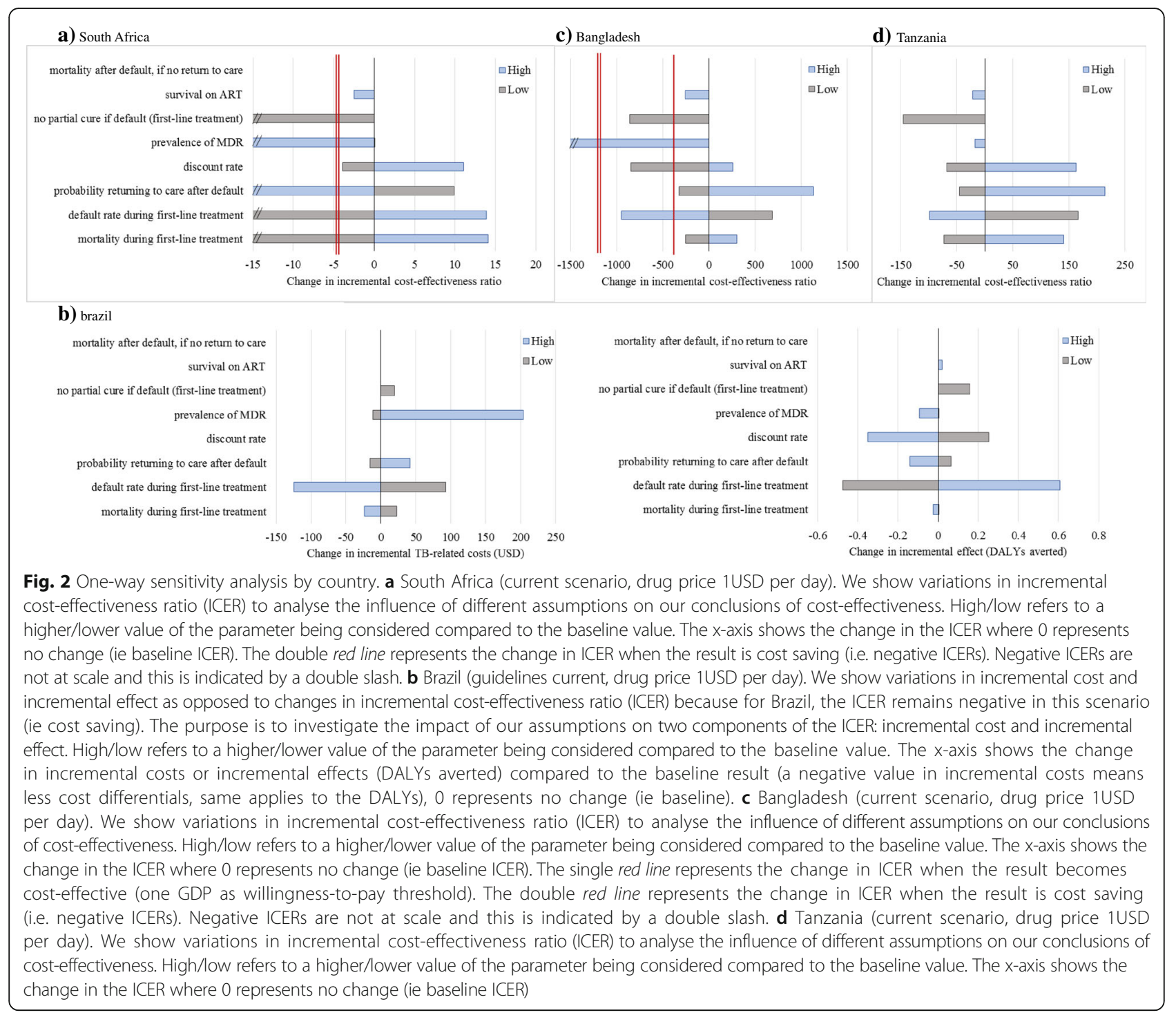

community-based. Individual health benefits are positive but modest.

Our findings are line with other recent studies that, contrary to earlier efforts, suggest that the health benefits (including population level) of regimen shortening are likely to be limited [11]. However, in light of the post2015 TB control strategy that aims for 'no affected families facing catastrophic costs due to TB' by 2025, we highlight the importance of the economic benefits of regimen shortening to patients. For example, in South Africa, $37 \%$ of TB patients were found to incur catastrophic costs; [17] and thus reducing costs by $25 \%$ may prevent considerable numbers falling into poverty because of contracting TB.

The difference in health service costs between settings highlights the importance of accounting for setting-specific resource use, health service and demand constraints.
Previous efforts, have assumed that any health service costs could be substantial and if usefully channeled back into other TB services - may have substantial impact [9]. Our findings are more modest and variable, but it should be noted that any savings remain critical, in the current situation where most current TB control programmes are substantially underfunded [1]. Paradoxically, incorporating a 'real world' perspective results in new regimens having lower economic benefits. However, one of the reasons for poor guideline adherence may be substantial constraints to $\mathrm{TB}$ treatment delivery, and so even freeing up modest resources in these settings may be important to improve TB treatment delivery more generally.

Drug prices have an important impact on our findings. However, to date, there is no public information on what the future cost of such a regimen would be or whether it 


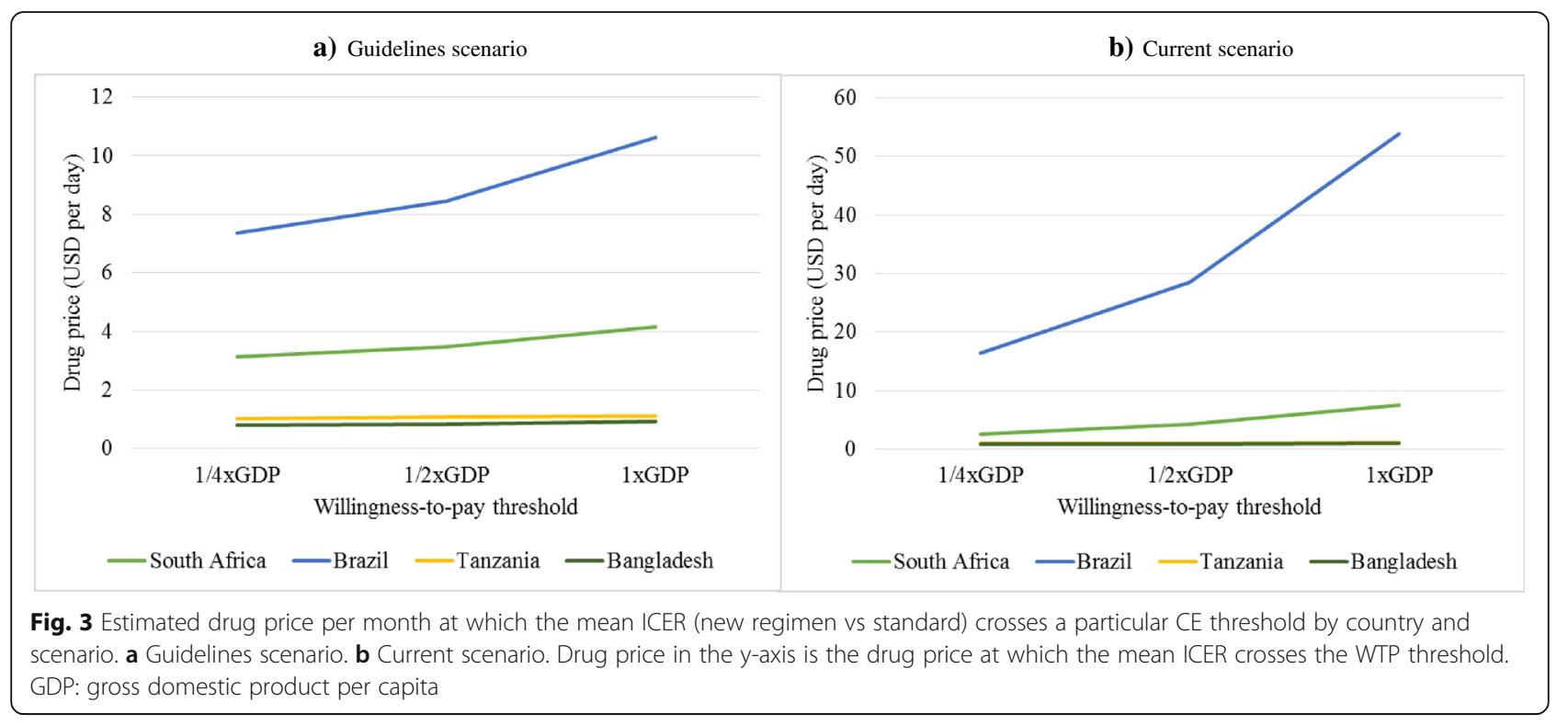

will vary by setting. Initial estimates of previously tested shortened regimens priced these regimens between USD10 and USD25 per month. We assumed a price of USD30 to provide a conservative point estimate of drug costs. However, as there is a high degree of uncertainty around price, we conducted a threshold analysis. Here we found that the threshold price per day was substantially higher in those settings where treatment delivery costs were higher (South Africa, USD10; Brazil, USD57); this threshold was sensitive to the adherence to guidelines assumptions. For those settings with lower treatment delivery costs (e.g. Tanzania and Bangladesh), USD1 per day was the maximum price for cost-effectiveness, but this threshold is sensitive to the uncertainty observed in effect estimates.

Our study has several limitations. We excluded benefits in children or in the prevention of downstream transmission and acquired resistance. The additional benefits due to transmission prevented has been estimated to be low in previous studies [11, 28], The benefits from reductions in acquired resistance are highly uncertain. This is in part due to lack of data on the probability of acquiring resistance, particularly where the precise regimen remains undefined. Once regimen profiles become available this will be an important consideration for further analyses. At this point, we are presenting conservative results, and it is possible that higher regimen prices may be cost-effectiveness once these benefits are taken into account. However, the additional benefits due to transmission prevented has been estimated to be low, while there is significant uncertainty on the effect of new regimens on future acquired resistance trends [11, 28]. With regards to benefits due to acquired resistance prevented, the magnitude of these benefits will depend exclusively on the drug regimen being introduced and will be an important consideration for further analyses. We did not include programme costs of new drug introduction (i.e. system-wide costs allowing the new regimen to be introduced, such as development of new treatment guidance or setting up new monitoring systems) nor did we examine the influence of alternative approaches to treatment observation going forward. In the case of the former, this exclusion may overestimate cost savings. However, any introduction cost, or startup cost, would be a one-off occurrence which would be discounted over time. In the case of the latter, where lower cost methods of observation are introduced in both base case and the alternative, cost savings may also be reduced.

\section{Conclusions}

A four-month non-inferior first-line TB regimen is likely to be cost saving or cost-effective in many country settings. This benefit is more marked in middle income countries, like South Africa and Brazil, where health service delivery costs are higher. Adherence to TB treatment guidelines is a key determinant of cost-effectiveness when considering the introduction of shortened regimens. In low income countries, like Tanzania and Bangladesh, drug price is likely to be critical for cost-effectiveness. In terms of the post2015 global TB targets, the most notable benefit of shortened regimens is to reduce the economic burden on households. In reaching these conclusions, we adopted an approach that considers individual and health service utilisation characteristics as well as societal costs using country-specific information, allowing us to tailor the analysis and conclusions to specific 'real world' settings. 


\section{Additional files}

Additional file 1: Supporting information (SI). Cost and cost-effectiveness of tuberculosis treatment shortening: a model-based analysis Gomez GB et al. August 2016. (DOCX $1955 \mathrm{~kb})$

Additional file 2: CHEERS checklist and technical appendix including additional results. (DOCX $16 \mathrm{~kb}$ )

\section{Abbreviations}

ART: Antiretroviral treatment; CP: Continuation phase of a six-month first line regimen (four last months); CS: Cost saving; DALY: Disability-adjusted life-year; DOT: Directly observed therapy; DST: Drug sensitivity testing; GDP: Gross domestic product; HIV: Human immunodeficiency virus; ICER: Incremental costeffectiveness ratio; IP: Intensive phase of a six-month first line regimen (first two months); MDR-TB: Multi-drug resistant tuberculosis; mo: Months; Pr: Probability; RIF: Rifampin; Rx: Treatment; SD: Standard deviation; TB: Tuberculosis; USD: US dollar; WTP: Willingness to pay

\section{Acknowledgements}

The authors are grateful to the TB Alliance staff for guiding us through the drug development pathways and informing our analysis with contextual information. The authors would also like to thank especially Elizabeth Gardiner and Heiner Grosskurth for their continuous support. Most importantly, the authors are very grateful to all the patients and healthcare professionals in Rio de Janeiro, Mwanza, Dhaka, and across South Africa for their time and dedication.

\section{Funding}

This work was supported by the Global Alliance for TB Drug Development. RGW is funded the Medical Research Council (UK) (MR/J005088/1), the Bill and Melinda Gates Foundation (TB Modelling and Analysis Consortium: OPP1084276), and CDC/PEPFAR via the Aurum Institute (U2GPS0008111). The funders had no role in study design, data collection and analysis, decision to publish, or preparation of the manuscript.

\section{Availability of data and materials}

All data supporting this analysis are presented in the manuscript and Additional files. No additional data are available.

\section{Authors' contributions}

GBG/AV were responsible for the design, analysis and interpretation of the study, drafted the initial manuscript and approved the final manuscript. DWD, MLB, AZ, SS, NF, AT, MAI, SK, ES, GMK, RGW, WAW, and FGC were involved in design and interpretation of the study, revised the manuscript and approved the final manuscript.

\section{Competing interests}

WAW was affiliated with the Global Alliance for TB Drug Development, New York, USA during the initial stages of the study. WAW was not at USAID when the research for the current paper was conducted. The views and opinions expressed in this paper are those of the authors and not necessarily the views and opinions of the United States Agency for International Development. Other authors have no competing interests declared.

\section{Consent for publication}

Not applicable.

\section{Ethics approval and consent to participate}

The VALUE-TB study was approved by the Observational and Interventions Research Ethics Committee of the London School of Hygiene and Tropical Medicine, UK on the $19^{\text {th }}$ December 2012 (reference number: 6322). Separate local ethics approvals were obtained as follows:

1) Rio de Janeiro, Brazil: All data (healthcare and patient) were collected after approval by the Institutional Review Board at the Universidade Gama Filho in Rio de Janeiro and the Comitê de Ética em Pesquisa, Prefeitura do Rio de Janeiro. These approvals were granted on the $10^{\text {th }}$ May 2013 (268.778) and the $9^{\text {th }}$ July 2013 (164A/2013), respectively.

2) Dhaka, Bangladesh: Healthcare cost data were collected after approval by Bangladesh Medical Research Council was received on the $18^{\text {th }}$ February 2014 (BMRC/NREC/2013-2016/1552). Patient cost data were sourced from a study on TB patient costs and perceptions, funded by the TB Alliance and overseen by the Liverpool School of Tropical Medicine [3], ethics were obtained for this study from the Liverpool School of Tropical Medicine (10.75); and Bangladesh Medical Research Council (BMRC/NREC/20 10-20 r3/56).

3) Mwanza, Tanzania: Data collection in healthcare facilities was approved as part of an ongoing study of HIV care (including opportunistic infections) and chronic disease led by the LSHTM (Improving the health systems response to chronic diseases in Africa. LSHTM ethics reference number: 6141). Patient cost data were sourced from a study on TB patient costs and perceptions, funded by the TB Alliance and overseen by the Liverpool School of Tropical Medicine [3], ethics were obtained for this study from the Liverpool School of Tropical Medicine (10.75); and National Institute for Medical Research, Tanzania (NIMR/HQ/R. 8a/Nol. IXI 121 5)

4) South Africa: Data collected from the "Xpert for TB: Evaluating a New Diagnostic" (XTEND) trial [17, 18]. The study was approved by the research ethics committees of the University of Cape Town (363/2011), University of the Witwatersrand (M110827), LSHTM (6041; amendment A341), and the World Health organisation (RPC462).

Health department officials and facility managers provided permission to conduct the study in the selected facilities and written informed consent was obtained from respondents.

\section{Author details}

${ }^{1}$ Amsterdam Institute for Global Health and Development and Department of Global Health, Academic Medical Center, University of Amsterdam, Trinity Building C, Pietersbergweg 17, Amsterdam 1105 BM, The Netherlands. ${ }^{2}$ Department of Global Health and Development, London School of Hygiene and Tropical Medicine, London, UK. ${ }^{3}$ Department of Epidemiology, Johns Hopkins Bloomberg School of Public Health, Baltimore, USA. ${ }^{4}$ Federal University of Rio de Janeiro, Rio de Janeiro, Brazil. ${ }^{5}$ Tuberculosis Scientific League, Rio de Janeiro, Brazil. ${ }^{6}$ Health Economics Unit, School of Public Health \& Family Medicine, University of Cape Town, Cape Town, South Africa. ${ }^{7}$ McGill University, Montreal, Canada. ${ }^{8}$ BRAC Health Nutrition and Population Programme, BRAC Centre, Dhaka, Bangladesh. ${ }^{9}$ Mwanza Intervention Trials Unit, National Institute for Medical Research, Mwanza, Tanzania. ${ }^{10} \mathrm{~TB}$ Modelling Group, Department of Infectious Disease Epidemiology, London School of Hygiene and Tropical Medicine, London, UK. ${ }^{11}$ Global Alliance for TB Drug Development, New York, USA. ${ }^{12}$ KNCV Tuberculosis Foundation, The Hague, Netherlands. ${ }^{13}$ Present address: United States Agency for International Development, Washington, DC, USA.

Received: 10 March 2016 Accepted: 8 November 2016

Published online: 01 December 2016

\section{References}

1. World Health Organization. Global tuberculosis report 2014. Geneva: World Health Organization; 2014.

2. Lienhardt C, Vernon A, Raviglione MC. New drugs and new regimens for the treatment of tuberculosis: review of the drug development pipeline and implications for national programmes. Curr Opin Pulm Med. 2010;16(3):186-93.

3. Gospodarevskaya E, Tulloch O, Bunga C, Ferdous S, Jonas A, Islam S, et al. Patient costs during tuberculosis treatment in Bangladesh and Tanzania: the potential of shorter regimens. Int J Tuberc Lung Dis Off J Int Union Tuberc Lung Dis. 2014;18(7):810-7.

4. Gillespie SH, Crook AM, McHugh TD, Mendel CM, Meredith SK, Murray SR, et al. Four-month moxifloxacin-based regimens for drug-sensitive tuberculosis. N Engl J Med. 2014;371(17):1577-87.

5. Diacon AH, Pym A, Grobusch MP, de los Rios JM, Gotuzzo E, Vasilyeva I, et al. Multidrug-resistant tuberculosis and culture conversion with bedaquiline. N Engl J Med. 2014;371(8):723-32.

6. Gler MT, Skripconoka V, Sanchez-Garavito E, Xiao H, Cabrera-Rivero JL Vargas-Vasquez DE, et al. Delamanid for multidrug-resistant pulmonary tuberculosis. N Engl J Med. 2012;366(23):2151-60.

7. Diacon AH, Dawson R, von Groote-Bidlingmaier F, Symons G, Venter A, Donald PR, et al. 14-day bactericidal activity of PA-824, bedaquiline, pyrazinamide, and moxifloxacin combinations: a randomised trial. Lancet. 2012:380(9846):986-93.

8. Owens JP, Fofana MO, Dowdy DW. Cost-effectiveness of novel first-line treatment regimens for tuberculosis. Int J Tuberc Lung Dis Off J Int Union Tuberc Lung Dis. 2013;17(5):590-6. 
9. Salomon JA, Lloyd-Smith JO, Getz WM, Resch S, Sánchez MS, Porco TC, et al. Prospects for advancing tuberculosis control efforts through novel therapies. PLoS Med. 2006;3(8), e273.

10. Abu-Raddad LJ, Sabatelli L, Achterberg JT, Sugimoto JD, Longini IMJ, Dye $C$, et al. Epidemiological benefits of more-effective tuberculosis vaccines, drugs, and diagnostics. Proc Natl Acad Sci U S A. 2009; 106(33):13980-5.

11. Fofana MO, Knight GM, Gomez GB, White RG, Dowdy DW. Population-level impact of shorter-course regimens for tuberculosis: a model-based analysis. PloS One. 2014;9(5), e96389.

12. World Health Organization, Stop TB Initiative (World Health Organization). Treatment of tuberculosis: guidelines. 4th ed. Geneva: World Health Organization; 2010. p. 147.

13. Fox W, Ellard GA, Mitchison DA. Studies on the treatment of tuberculosis undertaken by the British Medical Research Council tuberculosis units, 1946-1986, with relevant subsequent publications. Int J Tuberc Lung Dis Off J Int Union Tuberc Lung Dis. 1999;3(10 Suppl 2):S231-279.

14. Kumaranayake $L$. The real and the nominal? Making inflationary adjustments to cost and other economic data. Health Policy Plan. 2000;15(2):230-4.

15. World Bank. Indicators data [Internet]. [cited 2014 Aug 2]. Available from: http://data.worldbank.org/indicator/

16. Trajman A, Bastos ML, Belo M, Calaça J, Gaspar J, Dos Santos AM, Dos Santos CM, Brito RT, Wells WA, Cobelens FG, Vassall A, Gomez GB. Shortened first-line TB treatment in Brazil: potential cost savings for patients and health services. BMC Health Serv Res. 2016;16:27.

17. Foster N, Vassall A, Cleary S, Cunnama L, Churchyard GJ, Sinanovic E. The economic burden of TB diagnosis and treatment in South Africa. Soc Sc Med. 2015;130, e27.

18. Vassall A, Siapka M, Foster N, Fielding K, McCarthy K, Shillington L, et al. Xpert MTB/RIF scale-up in South Africa: impact on system-wide resource use and cost. Prep.

19. Zwerling A, Ferdous S, Basher AK, Islam S, Islam MA, Gomez GB, et al. Delivering first line TB treatment in Bangladesh: Facility costs and community health workers. Prep.

20. Wandwalo E, Robberstad B, Morkve O. Cost and cost-effectiveness of community based and health facility based directly observed treatment of tuberculosis in Dar es Salaam, Tanzania. Cost Eff Resour Alloc CE. 2005;3:6.

21. Rosen S, Long L, Sanne I. The outcomes and outpatient costs of different models of antiretroviral treatment delivery in South Africa. Trop Med Int Health TM IH. 2008;13(8):1005-15.

22. Long L, Fox M, Sanne I, Rosen S. The high cost of second-line antiretroviral therapy for HIV/AIDS in South Africa. AIDS Lond Engl. 2010;24(6):915-9.

23. Rosen S, Larson B, Rohr J, Sanne I, Mongwenyana C, Brennan AT, et al. Effect of antiretroviral therapy on patients' economic well being: five-year followup. AIDS Lond Engl. 2013;26.

24. Rosen $\mathrm{S}$, Larson B, Brennan A, Long L, Fox M, Mongwenyana C, et al. Economic outcomes of patients receiving antiretroviral therapy for HIV/AIDS in South Africa are sustained through three years on treatment. PloS One. 2010:5(9), e12731.

25. Edejer TT-T, World Health Organization, editors. Making choices in health: WHO guide to cost-effectiveness analysis. Geneva: World Health Organization; 2003. $312 \mathrm{p}$.

26. Husereau D, Drummond M, Petrou S, Carswell C, Moher D, Greenberg D, et al. Consolidated Health Economic Evaluation Reporting Standards (CHEERS)explanation and elaboration: a report of the ISPOR Health Economic Evaluation Publication Guidelines Good Reporting Practices Task Force. Value Health J Int Soc Pharmacoeconomics Outcomes Res. 2013;16(2):231-50.

27. NICE International. Methods for Economic Evaluation Project (MEEP). Bill and Melinda Gates Foundation; 2014. http://www.idsihealth.org/wp-content/ uploads/2015/01/MEEP-report.pdf.

28. Shrestha S, Knight GM, Fofana M, Cohen T, White RG, Cobelens F, et al. Drivers and trajectories of resistance to new first-line drug regimens for tuberculosis. Open Forum Infect Dis. 2014;1 (2):ofu073.

29. Steingart KR, Henry M, Ng V, Hopewell PC, Ramsay A, Cunningham J, et al. Fluorescence versus conventional sputum smear microscopy for tuberculosis: a systematic review. Lancet Infect Dis. 2006:6(9):570-81.

30. Shafer RW, Edlin BR. Tuberculosis in patients infected with human immunodeficiency virus: perspective on the past decade. Clin Infect Dis Off Publ Infect Dis Soc Am. 1996;22(4):683-704.

31. World Health Organization. Global tuberculosis control: epidemiology, strategy, financing: WHO report 2009. Geneva: World Health Organization; 2009.
32. Chonde TM, Basra D, Mfinanga SGM, Range N, Lwilla F, Shirima RP, et al. National anti-tuberculosis drug resistance study in Tanzania. Int J Tuberc Lung Dis Off J Int Union Tuberc Lung Dis. 2010;14(8):967-72.

33. Corbett EL, Watt CJ, Walker N, Maher D, Williams BG, Raviglione MC, et al. The growing burden of tuberculosis: global trends and interactions with the HIV epidemic. Arch Intern Med. 2003;163(9):1009-21.

34. Abdool Karim SS, Churchyard GJ, Karim QA, Lawn SD. HIV infection and tuberculosis in South Africa: an urgent need to escalate the public health response. Lancet. 2009;374(9693):921-33.

35. Cattamanchi A, Dowdy DW, Davis JL, Worodria W, Yoo S, Joloba M, et al. Sensitivity of direct versus concentrated sputum smear microscopy in HIV-infected patients suspected of having pulmonary tuberculosis. BMC Infect Dis. 2009;9:53.

36. Steingart KR, Sohn H, Schiller I, Kloda LA, Boehme CC, Pai M, et al. Xpert ${ }^{\oplus}$ MTB/RIF assay for pulmonary tuberculosis and rifampicin resistance in adults. Cochrane Database Syst Rev Online. 2013;1, CD009593.

37. Espinal MA, Kim SJ, Suarez PG, Kam KM, Khomenko AG, Migliori GB, et al. Standard short-course chemotherapy for drug-resistant tuberculosis: treatment outcomes in 6 countries. JAMA. 2000;283(19):2537-45.

38. Akksilp S, Karnkawinpong O, Wattanaamornkiat W, Viriyakitja D, Monkongdee $\mathrm{P}$, Sitti W, et al. Antiretroviral therapy during tuberculosis treatment and marked reduction in death rate of HIV-infected patients, Thailand. Emerg Infect Dis. 2007;13(7):1001-7.

39. Wells CD, Cegielski JP, Nelson LJ, Laserson KF, Holtz TH, Finlay A, et al. HIV infection and multidrug-resistant tuberculosis: the perfect storm. J Infect Dis. 2007;196 Suppl 1:S86-107.

40. Dye C, Garnett GP, Sleeman K, Williams BG. Prospects for worldwide tuberculosis control under the WHO DOTS strategy. Directly observed short-course therapy. Lancet. 1998;352(9144):1886-91.

41. Dye C, Williams BG. Criteria for the control of drug-resistant tuberculosis. Proc Natl Acad Sci U S A. 2000;97(14):8180-5.

42. Tiemersma EW, van der Werf MJ, Borgdorff MW, Williams BG, Nagelkerke NJD. Natural history of tuberculosis: duration and fatality of untreated pulmonary tuberculosis in HIV negative patients: a systematic review. PloS One. 2011;6(4), e17601.

43. Hong Kong Chest Service/Tuberculosis Research Centre, Madras/British Medical Research Council. A controlled trial of 2-month, 3-month, and 12-month regimens of chemotherapy for sputum-smear-negative pulmonary tuberculosis. Results at 60 months. Am Rev Respir Dis. 1984;130(1):23-8.

44. Singapore Tuberculosis Service/British Medical Research Council. Long-term follow-up of a clinical trial of six-month and four-month regimens of chemotherapy in the treatment of pulmonary tuberculosis. Singapore Tuberculosis Service/British Medical Research Council. Am Rev Respir Dis. 1986;133(5):779-83.

45. East and Central African/British Medical Research Council Fifth Collaborative Study. Controlled clinical trial of 4 short-couse regimens of chemotherapy (three 6-month and one 8-month) for pulmonary tuberculosis. Tubercle. 1983;64(3):153-66.

46. Marx FM, Dunbar R, Enarson DA, Beyers N. The rate of sputum smearpositive tuberculosis after treatment default in a high-burden setting: a retrospective cohort study. PloS One. 2012;7(9), e45724.

47. Nathanson E, Lambregts-van Weezenbeek C, Rich ML, Gupta R, Bayona J, Blöndal $\mathrm{K}$, et al. Multidrug-resistant tuberculosis management in resourcelimited settings. Emerg Infect Dis. 2006;12(9):1389-97.

48. Suárez PG, Floyd K, Portocarrero J, Alarcón E, Rapiti E, Ramos G, et al. Feasibility and cost-effectiveness of standardised second-line drug treatment for chronic tuberculosis patients: a national cohort study in Peru. Lancet. 2002; 359(9322):1980-9.

49. Menzies NA, Berruti AA, Berzon R, Filler S, Ferris R, Ellerbrock TV, et al. The cost of providing comprehensive HIV treatment in PEPFAR-supported programs. AIDS Lond Engl. 2011;25(14):1753-60.

50. Bratt JH, Torpey K, Kabaso M, Gondwe Y. Costs of HIV/AIDS outpatient services delivered through Zambian public health facilities. Trop Med Int Health TM IH. 2011:16(1):110-8.

51. Chandrashekar S, Guinness L, Pickles M, Shetty GY, Alary M, Vickerman P, et al. The costs of scaling up HIV prevention for high risk groups: lessons learned from the Avahan Programme in India. PloS One. 2014;9(9), e106582.

52. Siapka $\mathrm{M}$, Remme $\mathrm{M}$, Obure $\mathrm{CD}$, Maier CB, Dehne KL, Vassall A. Is there scope for cost savings and efficiency gains in HIV services? A systematic review of the evidence from low- and middle-income countries. Bull World Health Organ. 2014;92(7):499-511AD. 
53. Rosen S, Ketlhapile M, Sanne I, DeSilva MB. Cost to patients of obtaining treatment for HIV/AIDS in South Africa. South Afr Med J Suid-Afr Tydskr Vir Geneeskd. 2007;97(7):524-9.

54. Republic of South Africa. Department of Health. National tuberculosis management guidelines 2014. Pretoria: Department of Health; 2014.

55. Department of Health South Africa. The South African Antiretroviral Treatment Guidelines [Internet]. 2013. Available from: http://www.sahivsoc. org/SubHeader?slug=ndoh-and-who-guidelines. Accessed 29 Nov 2016

56. The United Republic of Tanzania Ministry of Health and Social Welfare. Manual of the National Tuberculosis and Leprosy Programme in Tanzania [Internet]. 5th ed. [Internet]. 2006. Available from: http://www.who.int/hiv/ pub/guidelines/tanzania_tb.pdf. Accessed 29 Nov 2016.

57. The United Republic of Tanzania Ministry of Health and Social Welfare. National guidelines for the management of HIV and AIDS. 4th ed. [Internet]. 2012. Available from: https://aidsfree.usaid.gov/sites/default/files/hts_policy_tanzania. pdf. Accessed 29 Nov 2016.

58. National AIDS /STD Program, Directorate General of Health Services, Ministry of Health and Family Welfare. National guidelines of antiretroviral therapy Bangladesh. Dhaka, Bangladesh [Internet]. 2011. Available from: https:// www.medbox.org/national-guidelines-of-art/download.pdf. Accessed 29 Nov 2016.

59. National Tuberculosis Control Programme Directorate General of Health Services Ministry of Health and Family Welfare Dhaka, Bangladesh. National Guidelines and Operational Manual for Tuberculosis Control. 4th ed. Dhaka: 2011.

60. Brasil. Ministério da Saúde. Secretaria de Vigilância em Saúde. Departamento de Vigilância Epidemiológica. Manual de recomendações para o controle da tuberculose no Brasil / Ministério da Saúde, Secretaria de Vigilância em Saúde, Departamento de Vigilância Epidemiológica. - Brasília : Ministério da Saúde, 2011.

61. Ministério da Saúde, Brazil. Recomendações de terapia antirretroviral para adult os vivendo com HIV/aids no Brasil [Internet]. 2012. Available from: http://www.aids.gov.br/sites/default/files/anexos/publicacao/2012/52140/ consenso_adulto2012_principais_mudancas_pdf_11946.pdf. Accessed 29 Nov 2016.

62. Department of Health. Multi-drug resistant tuberculosis. A policy framework on decentralised deinstitutionalised management for South Africa. South Africa: Department of Health; 2011.

63. Pan American Health Organization, World Health Organization. Antiretrovira treatment in the spotlight: a public health analysis in Latin America and the Caribbean, 2013. 2013

64. Njeka N. MDR treatment coverage in South Africa 2013. 2013.

\section{Submit your next manuscript to BioMed Central and we will help you at every step:}

- We accept pre-submission inquiries

- Our selector tool helps you to find the most relevant journal

- We provide round the clock customer support

- Convenient online submission

- Thorough peer review

- Inclusion in PubMed and all major indexing services

- Maximum visibility for your research

Submit your manuscript at www.biomedcentral.com/submit 